\title{
Logic and Engineering of Natural Language Semantics 2004
}

This part of this volume is made up of revised and refined versions of the papers submitted to the First International Conference of Logic and Engineering of Natural Language Semantics, LELNS2004, held in Kanazawa, Japan, on May 31, 2004. LELNS2004 featured theories of Dynamic Semantics and their applications to natural language analysis and natural language engineering. Dynamic Semantics is one of the most vivid and promising areas of current research in natural language semantics. Some representative approaches within this general area are:

- Discourse Representation Theory (DRT),

- Segmented Discourse Representation Theory (SDRT),

- Dynamic Predicated Logic (DPL),

- Context Change Semantics (CCS), and

- Update Semantics (US).

This section is made up of eight papers presented at LENLS. They were revised several times by the authors, with input from the Organizing Committee: Norihiro Ogata (Osaka University), Yasuo Nakayama (Osaka University), Katsuhiko Yabushita (Naruto University of Education), and Eric McCready (Univeristy of Texas).

I wish to express my gratitude to all the members of the Organizing Committee, all those who submitted papers, and all the members of the Orginizing Committee of the International Workshops of the Annual Conference of JSAI.

I also thank the JSAI for providing the opportunity to hold an internatoinal workshop on Dynamic Semantics in Japan. 